\title{
Study on the Performance Evaluation System of Patent Strategy of High \& New Technology Enterprise Clusters
}

\author{
Jian-long WU, Hong-qi WANG and Yu GUO \\ Research Center for High \& New Technology Industry Development, Harbin University of Science \\ and Technology, Harbin, China \\ wujl1981@sohu.com
}

Keywords: high \& new technology enterprise clusters; patent strategy, performance evaluation

\begin{abstract}
Strategic performance evaluation is the key link of making patent strategy and dynamic management of high-tech enterprise clusters. Therefore, on the basis of analyzing the performance factors of high-tech enterprise clusters, the article designed the cluster patent strategy performance evaluation index system and constructed the performance evaluation method by using anal ytic hierarchy process and fuzzy comprehensive evaluation comprehensively. At last, the article conducted the empirical research based on Heilongjiang province medicine cluster, in order to provide method supporting for patent strategy management of regional high-tech enterprise clusters.
\end{abstract}

\section{Introduction}

With the rapid development of science and technology and further strengthen of economic globalization in the knowledge economy era, high \& new technology enterprise cluster that has become important industrial organization forms in enhancing international competitiveness and realizing independent innovation strategy of high \& new technology industries in China have developed rapidly. The mark of independent innovation is patent technology acquisition [1-3], so strengthen the patent strategy management is also the important strategic measure for high \& new technology enterprise cluster participating in global competition. However, a series of problems restricted long-term and rapid growth of the high \& new technology enterprise cluster to a large extent at present, such as: patent consciousness deficiency, low level of patent strategy management, core patent technology insufficient and patent infringement [4]. The scientific and effective evaluation for patent strategy performance of high \& new technology enterprise cluster is the basis of designing and selecting cluster patent strategy [5]. This is beneficial to master the implement dynamic of high \& new technology enterprise cluster patent strategy, so as to control and adjust the patent strategy.

\section{Performance Factors Analysis of High \& New Technology Enterprise Clusters Patent Strategy}

High \& new technology enterprise cluster patent strategy serve cluster of independent innovation and sustainable development from four strategic dimensions [6-8]. The four dimensions are patent creation, utilization, protection and management. So, the performance factors of cluster patent strategy mainly reflected in these four areas.

Cluster Patent Creation. Patent development is first step of patent strategy implementation of high \& new technology enterprise cluster. However, the effects of patent creation are reflected through the patent application and patent authorization [9]. Patent applications reflect the level of activity of cluster patent development and patent authorization especially invention patents authorized reflect the development quality of cluster patent development.

Cluster Patent Utilization. Cluster patent focuses on the patent transform the value creation continually, that is to say, it need to realize patent effectiveness maximization by making full of patent attributes and system. Using the products or services which have possessed independent 
intellectual property to participate in the competition of global value chain and upgrade and obtain high profits continually [10].

Cluster Patent Protection. On one hand, high \& new technology enterprise cluster should make full use of patent system to protect its innovation advantage in the global value chain; on the other hand, it should find optimal protection between promoting cluster innovation and keeping technology flow appropriately. Thus, Cluster usually established multi-layer comprehensive patent protection system on the basis of patent system of international, domestic, industry association and cluster itself. The final performance of cluster mainly reflected in the quantity of patent infringement and litigation amount.

Cluster Patent Management. Implementation of patent strategy aims to promote the cluster' overall patent management capabilities, which urge more cluster enterprise to posses more complete patent management departments and system and form more developed intellectual property system to serve the cluster patent management.

\section{Evaluation Index Design of Patent Strategy Performance for High \& New Technology Enterprise Cluster}

Constructing performance evaluation index system scientifically is the premise and foundation of performance evaluation. Patent Strategy Performance of high \& new technology enterprise cluster throughout the strategy implementation process, so, comprehensive evaluation index system should reflect the cluster patent creation, use, protection and management effectiveness. Taking into account the strategic performance mainly reflects the good or bad effects of the implementation of cluster patent strategy; that is to say, it mainly reflects performance improvement of main strategic dimensions compared with the previous strategy period. Thus, the article mainly uses incremental proportion index when designing the secondary indicators, as the table 1 shows.

Table 1 Evaluation index system of patent strategy implementation of high \& new technology enterprises cluster

\begin{tabular}{|c|c|c|}
\hline Evaluation objectives & Primary indicators & Secondary indicators \\
\hline \multirow{10}{*}{$\begin{array}{l}\text { Performance evaluation } \\
\text { of patent strategy for } \\
\text { high \& new technology } \\
\text { enterprise cluster U }\end{array}$} & \multirow{3}{*}{ patent creation $\mathrm{X}_{1}$} & Growth rate of patent application $\mathrm{x}_{11}$ \\
\hline & & Growth rate of invention patent authorization $\mathrm{x}_{12}$ \\
\hline & & Growth rate of total patent authorization $\mathrm{x}_{13}$ \\
\hline & \multirow{3}{*}{ patent utilization $\mathrm{X}_{2}$} & Growth rate of patented product sales revenue \\
\hline & & Growth rate of patent income permission or transfer $\mathrm{x}_{22}$ \\
\hline & & Growth rate of Patent technology standards $x_{23}$ \\
\hline & \multirow{2}{*}{ patent protection $\mathrm{X}_{3}$} & Decline rate of patent infringement $x_{31}$ \\
\hline & & Decline rate of patent litigation compensation $\mathrm{x}_{32}$ \\
\hline & \multirow[b]{2}{*}{ patent management $\mathrm{X}_{4}$} & Growth rate of patent agency $\mathrm{x}_{41}$ \\
\hline & & $\begin{array}{l}\text { Growth rate of cluster enterprises possessing patent } \\
\text { management department } \mathrm{x}_{42}\end{array}$ \\
\hline
\end{tabular}

\section{Selection and Construction of Evaluation Method of Patent Strategy Performance for High \& New Technology Enterprise Cluster}

Performance evaluation of patent strategy of high \& new technology enterprise cluster belongs to multi-objective evaluation and the accuracy of performance evaluation needs to determine the weight of indicators and the level of growth rate do not have clear standards, so, the evaluation need to give full play to the wisdom of experts in the field of patent strategy management. Analyzing the advantages and disadvantages of various evaluation methods and using of analytic hierarchy process and fuzzy comprehensive evaluation method comprehensively can meet the requirements for this evaluation. The article will show the evaluation process based on the pharmaceutical industry cluster in Heilongjiang province. 
Determination of Indicators Weight. In order to determine the weight of each indicator in the evaluation indicator system, we invited 25 experts in the field of science and technology management who run at Heilongjiang intellectual property office and Heilongjiang Science and Technology Agency to evaluate the index weight index. At last, we obtained judgment matrix according to calculation and finishing, as the table 2 shows.

Table 2 Estimation matrices of first level index

\begin{tabular}{c|ccccc}
\hline $\mathrm{U}$ & $\mathrm{X}_{1}$ & $\mathrm{X}_{2}$ & $\mathrm{X}_{3}$ & $\mathrm{X}_{4}$ & $\mathrm{~W}$ \\
\hline $\mathrm{X}_{1}$ & 1 & $1 / 6$ & $1 / 4$ & $1 / 2$ & 0.0692 \\
$\mathrm{X}_{2}$ & 6 & 1 & 3 & 5 & 0.5637 \\
$\mathrm{X}_{3}$ & 4 & $1 / 3$ & 1 & 3 & 0.2576 \\
$\mathrm{X}_{4}$ & 2 & $1 / 5$ & $1 / 3$ & 1 & 0.1095 \\
\hline
\end{tabular}

$\lambda \max =4.0788 \mathrm{CI}=0.0263 \mathrm{RI}=0.90 \mathrm{CR}=0.0292<0.1$ through the consistency test, so, the weight of primary indicators are: $A=\{0.0692,0.5637,0.2576,0.1095\}$. The judgment matrix of secondary indicators as the table 3 shows.

Table 3 Estimation matrices of second level index

\begin{tabular}{c|cccc}
\hline $\mathrm{X}_{1}$ & $\mathrm{x}_{11}$ & $\mathrm{x}_{12}$ & $\mathrm{x}_{13}$ & $\mathrm{~W}$ \\
\hline $\mathrm{x}_{11}$ & 1 & 5 & 3 & 0.6483 \\
$\mathrm{x}_{12}$ & $1 / 5$ & 1 & $1 / 2$ & 0.1220 \\
$\mathrm{x}_{13}$ & $1 / 3$ & 2 & 1 & 0.2297 \\
\hline
\end{tabular}

$\lambda_{\max }=3.0037 \mathrm{CI}=0.0019 \mathrm{RI}=0.58 \mathrm{CR}=0.0033<0.1$ through the consistency test, so, the weight of secondary indicators are: $a_{1}=\{0.6483,0.1220,0.2297\}, a_{2}=\{0.6738,0.1007,0.2255\}, a_{3}=\{0.3333$, $0.6667\}, \mathrm{a}_{4}=\{0.1667,0.8333\}$.

Determination of Fuzzy Matrix. The article evaluated the classification into four grades, namely it established an evaluation set $\mathrm{V}=\{\mathrm{V} 1, \mathrm{~V} 2, \mathrm{~V} 3, \mathrm{~V} 4\}=\{$ optimality, good, medium, difference $\}$, in which optimality represent the level is higher than the national average, good represent the level is slightly higher than the national average, medium represent the level is almost the same as the national average and difference represent the level is lower than the national average. We still invited 25 experts to evaluate the four grades of each layer indicators and calculate the evaluation matrix of first layer according to the percentage that the number of each level in the total number.

$$
\begin{gathered}
R_{1}=\left[\begin{array}{cccc}
0 & 0.24 & 0.4 & 0.36 \\
0 & 0.2 & 0.28 & 0.52 \\
0 & 0.2 & 0.48 & 0.32
\end{array}\right], \mathrm{n}_{\mathrm{z}}=\left[\begin{array}{cccc}
0 & 0.08 & 0.32 & 0.6 \\
0 & 0 & 0.36 & 6.64 \\
0 & 0.08 & 0.12 & 0.0
\end{array}\right], \\
R_{\mathrm{V}}=\left[\begin{array}{cccc}
0 & 0.04 & 0.24 & 0.72 \\
0 & 0 & 0.44 & 0.56
\end{array}\right] R_{4}=\left[\begin{array}{cccc}
0 & 0.12 & 0.4 & 0.48 \\
0 & 0.04 & 0.12 & 0.84
\end{array}\right] .
\end{gathered}
$$

Fuzzy Comprehensive Evaluation. The article implemented the primary fuzzy evaluation of patent strategy for pharmaceutical cluster in Heilongjiang Province. $B_{1}=a 1 \bullet R_{1}=(0,0.24,0.4,0.36)$, $\mathrm{B}_{2}=\mathrm{a}_{2} \bullet \mathrm{R}_{2}=(0,0.08,0.32,0.6), \mathrm{B}_{3}=\mathrm{a}_{3} \bullet \mathrm{R}_{3}=(0,0.04,0.44,0.56), \mathrm{B}_{4}=\mathrm{a}_{4} \bullet \mathrm{R}_{4}=(0,0.12,0.1667,0.8333)$

Based on the above principle, we implemented the secondary fuzzy evaluation.

$\mathrm{B}=\mathrm{A} \bullet \mathrm{R}=(0,0.1095,0.32,0.5637)$

According to the analysis, the article obtained the following conclusions: Strategic performance of patent creation of pharmaceutical cluster in Heilongjiang Province is in the level of lower than national medium; Strategic performance of patent application of pharmaceutical cluster in Heilongjiang Province is in the level of national deviation; Strategic performance of patent utilization of pharmaceutical cluster in Heilongjiang Province is in the level of lower than national medium; Strategic performance of patent management of pharmaceutical cluster in Heilongjiang province is in the level of national deviation. According to the principle of maximum membership degree, the 
article can obtain the conclusion that patent Strategic performance of pharmaceutical cluster in Heilongjiang Province is in the level of worse.

\section{Conclusion}

Performance management is the key link of patent strategy management for high \& new technology enterprise cluster. Combining with the patent strategic emphasis in the innovation process, the article divided the patent strategic performance of cluster into patent creation, patents utilization, patent protection and patent management and highlighted the increment of patent performance in certain strategic phase. When evaluating the patent strategy performance of cluster, we need to give full play to the wisdom of experts who are familiar with this area and analytic hierarchy process and fuzzy comprehensive evaluation method comprehensively can meet the requirements for this evaluation better. The article analyzed and evaluated the patent strategy performance based on the pharmaceutical cluster in Heilongjiang province and verified the scientific validity of the evaluation indicators and methods.

\section{Acknowledgment}

This research was supported by the National Natural Science Foundation (71171069), the Humanities and Social Sciences Foundation of Ministry of Education (12YJC630238), the Heilongjiang Philosophy and Social Sciences Foundation (11D074, 11C033), Science and Technology Research Project of Heilongjiang Province (GC12D212), Academic Innovation Team Construction Plan of Philosophy and Social Sciences of University in Heilongjiang Province, the Young Academic Backbone Support Project of University of Heilongjiang Province in 2013, and the Youth Fund of Harbin University of Science and Technology (2011YF051).

\section{References}

[1] Michael Potter, Competitive advantage. Beijing: China Financial and Economic Press(1988).

[2] Wernerfelt B. A resource-based view of the firm," Strategic management journal, Vol. 5 (1984), p. 171-180.

[3] Prahalad C. K., Hamel G. "The core competence of the corporation," Harvard business review, Vol. 68 (1990), p. 79-90.

[4] Linqing Liu, Liwen Tan. Rent, power and performance_- thinking competitive advantage in the context of global value chains, China Industrial Economy, Vol. 25 (2008), p. 50-58.

[5] Weiping $\mathrm{Yu}$, Miao Cui. Value chain optimization analysis based on the enterprise capabilities Under Economic Globalization, China Industrial Economy, Vol. 20 (2003), p. 42-47.

[6] Jian Lin. Enterprise strategy network based on core competence-corporate strategic management model of network economy era, China Soft Science, Vol. 20 (2003), p.68-73.

[7] Hongqi Wang, Theory research on enterprise comprehensive advantage, Management World, Vol. 21 (2005), p.151-152.

[8] Williamson Oliver E. Strategy research: governance and competence perspectives, Strategic management journal, Vol. 20 (1999), p. 1087-1108.

[9] Dovev Lavie. Capability Reconfiguration: An Analysis of Incumbent Responses to Technological Change, Academy of Management Review, Vol.31 (2006), p.153-174.

[10] Hongqi Wang, Jianlong Wu. Research on the selection of corporate dominance advantage, China Soft Science, Vol. 25 (2010), p. 151-157. 